\title{
Relação entre o processo de ensino-aprendizagem-treinamento e o desenvolvimento do conhecimento tático no voleibol
}

CDD. 20.ed. 796.017
796.325

\author{
Cláudio Olívio Vilela LIMA ${ }^{* / * * * * *}$ \\ Hugo Cesar MARTINS-COSTA ${ }^{* * * * *}$ \\ Pablo J uan GRECO*
}

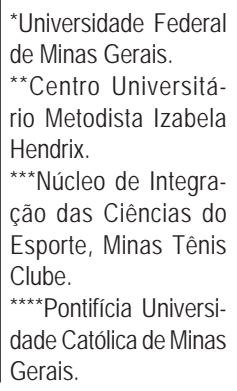

0 objetivo desse estudo foi verificar em que medida o processo de ensino-aprendizagem-treinamento utilizado em uma equipe feminina de voleibol favoreceu o desenvolvimento do conhecimento tático declarativo das atletas. Doze jogadoras (idade média 13,9 $\pm 0,3$ anos) pertencentes a um clube participaram da pesquisa. Para caracterizar o processo de ensino-aprendizagem-treinamento foram filmadas e posteriormente analisadas 17 sessões consecutivas de treinamento. Para verificar o desenvolvimento do conhecimento tático, utilizou-se o teste validado por PaULA (2001), sendo este aplicado no início e no final das sessões de treino registradas. Na análise das sessões de treino, as atividades relacionadas ao desenvolvimento da capacidade técnica ocuparam $57,5 \%$ do tempo total de treinamento, enquanto que em $29,9 \%$ do tempo foram desenvolvidas atividades com características de aperfeiçoamento tático. Para o conhecimento tático, não foi verificado aumento em nenhuma das variáveis medidas no teste. Esses resultados demonstraram que o treinador planificou suas sessões de forma a dedicar maior atenção ao componente técnico, sendo este contemplado especialmente através das atividades sem conexão com situações de jogo, como "fundamentos individuais" ou "combinação de fundamentos". A estrutura de treinamento utilizada parece não ter favorecido o aumento do nível de conhecimento tático declarativo no decorrer do período de treinamento avaliado.

Unitermos: Modelos de ensino; Jogos esportivos coletivos; Cognição e ação; Tomada de decisão.

\section{Introdução}

Os jogos esportivos coletivos, designação dada às modalidades tais como o basquetebol, futebol, futsal, voleibol e handebol, ocupam indubitavelmente um lugar de destaque dentro da cultura de movimento contemporânea (GARGANTA, 1995). Este grupo de modalidades esportivas está presente nos vários níveis do sistema de formação e treinamento esportivo, desde o esporte escolar até o alto nível de rendimento (GReCo \& BeNDA, 1998).

Os jogos esportivos coletivos são caracterizados pela presença frequente de situações de grande imprevisibilidade, fazendo com que os seus praticantes necessitem adotar permanentemente atitudes táticas e estratégicas (Greco \& Chagas, 1992). Embora em algumas modalidades, como o voleibol, sejam verificadas estruturas mais deterministas que outras modalidades onde há invasão do campo adversário (por exemplo, no futebol) ainda sim os problemas colocados nos diferentes momentos do jogo fazem com que seus praticantes precisem ajustar suas ações a cada situação tática apresentada (MESQUITA, 1996). Portanto, as ações no jogo sempre têm uma finalidade tática, de forma que a cognição e a ação se tornam inseparáveis (GRECO, 1999). Partindo dessa premissa, a tomada de decisão ganha importância dentro dos jogos esportivos coletivos, tornando crucial o seu desenvolvimento ao longo do processo de treinamento técnico-tático.

Pesquisas têm analisado mudanças na capacidade tática no decorrer do tempo ao serem implementadas diferentes formas de treinamento técnico-tático (French, Werner, Taylor, Hussey \& Jones, 1996; Harrison, Blakemore, Richards, Oliver, WilLIINSON \& Fellingham, 2004; Mendez-Gimenez, 1999; PeREZ-Morales \& Greco, 2007; Silva \& Greco, 2009; TURNER \& MARTINEK, 1992, 1999). Algumas variáveis 
relacionadas a essa capacidade são frequentemente testadas através de parâmetros como a competência de tomar decisões em situações reais durante o jogo (CoRrêa, Silva \& Paroli, 2004; Mesqutta, Graça, Gomes \& Cruz, 2005), bem como do conhecimento tático que os indivíduos apresentam em relação à modalidade que está sendo pesquisada (FrENCH \& THOMAS, 1987; FrENCH et al., 1996; HARRISON et al., 2004; SISTO \& Greco, 1995; Turner \& MartineK, 1992, 1999).

Dois tipos de conhecimento tático são considerados relevantes para o desempenho nas ações esportivas: o conhecimento declarativo e o conhecimento processual (TAVARES, Greco \& Garganta, 2006). O conhecimento declarativo é definido por STERNBERG (2000) como sendo o reconhecimento e o entendimento da informação real sobre os objetos, as ideias e os eventos no ambiente, como a localização dos jogadores em quadra, os objetivos e submetas do jogo. O conhecimento processual é caracterizado como informação sobre o modo de executar uma sequência de operações, ou seja, a compreensão e consciência de como realizar habilidades ou tarefas especificas (ANDerson, 2004; Sternberg, 2000). O desempenho nos jogos esportivos coletivos tem se correlacionado positivamente tanto com o conhecimento declarativo (FrenCH \& ThOMAS, 1987) quanto com o conhecimento processual (Iglesias, Moreno, Santos-Rosa, Cervello \& Del-Villar, 2005), acreditando-se que o conhecimento da ação favorece a base para o desempenho habilidoso (ANDERSON, 2004).

Em boa parte dos estudos, o conhecimento declarativo tem sido mensurado a partir de perguntas formuladas em questionários, relacionando-as com regras ou objetivos do jogo. Para a mensuração do conhecimento processual também tem se utilizado questionários, buscando, entretanto, relacionar as perguntas com a resolução de situações de jogo (FRENCH \& THOMAS, 1987; FrENCH et al., 1996; IGLESIAS et al., 2005; TURNER \& MARTINEK, 1992, 1999). Outra forma de se avaliar o conhecimento tático processual é através da própria ação motora, onde esta pode ser filmada e posteriormente avaliada por peritos (MoreirA, 2005; PEREZ-Morales \& Greco, 2007; Silva \& Greco, 2009).
Na última década, algumas pesquisas foram realizadas com o intuito de analisar sessões de treinamento técnico-tático em equipes de formação, sem que ocorressem intervenções por parte dos pesquisadores (Collet, Nascimento, Ramos \& Donegá, 2007; Martins-Costa, Lima, Matias \& Greco, 2007; Nascimento \& Barbosa, 2000; Perez-Morales \& Greco, 2007; SaAd, 2002; Silva \& Greco, 2009). Com base nesta abordagem, busca-se verificar como o treinador transforma conteúdos e objetivos em tarefas de treinamento, permitindo assim caracterizar o processo de ensino-aprendizagem-treinamento utilizado pelo mesmo. Ainda que neste grupo de estudos (Collet et al., 2007; Martins-Costa et al., 2007; Nascimento \& Barbosa, 2000; Perez-Morales \& Greco, 2007; SaAD, 2002; SiLVA \& Greco, 2009) a descrição do treinamento apresente uma vantagem relacionada à busca de um conhecimento mais ecológico que aquele obtido em outras investigações cujo conteúdo das sessóes é determinado pelos próprios investigadores, pouca atenção tem sido dada ao desenvolvimento do conhecimento tático no decorrer do período de treinamento analisado, de forma particular, do conhecimento declarativo. Adicionalmente, quando analisado o efeito do processo de ensino-aprendizagem-treinamento em jogos de não-invasão, há indícios de que estruturas de treinamento com ênfase tática apresentam vantagem para o desenvolvimento do conhecimento tático que as abordagens pautadas na técnica (FrENCH et al., 1996; McPherson \& French, 1991), embora ambos os modelos de ensino demonstrem contribuir neste sentido (FrENCH et al., 1996; HaRRISON et al., 2004; MCPHERSON \& FrenCH, 1991), o que reforça a dificuldade de se assumir uma dicotomia entre técnica e tática nos jogos esportivos coletivos (MESQUITA, Pereira \& Graça, 2009). Assim, o objetivo do presente estudo foi verificar em que medida o processo de ensino-aprendizagem-treinamento adotado por um treinador (mais centrado na técnica ou na tática) foi capaz de promover o desenvolvimento do conhecimento tático declarativo de atletas de voleibol no decorrer de 17 sessōes de treinamento técnico-tático.

\section{Métodos}

O presente estudo foi submetido e aprovado pelo Comitê de Ética em Pesquisa com seres humanos da Universidade Federal de Minas Gerais sob o protocolo CAAE-0121.0.203.000-07. Antes de iniciar a coleta dos dados, o treinador da equipe escolhida recebeu uma carta convite, contendo informações gerais sobre os objetivos do estudo. Posteriormente, as voluntárias e seus responsáveis foram também informados sobre 
a pesquisa e assinaram o termo de consentimento livre e esclarecido. Os pesquisadores acompanharam sucessivamente 17 sessões de treinamento técnicotático, sendo aplicados testes de conhecimento tático declarativo antes da $1^{\mathrm{a}}$ sessão e um dia após a $17^{\mathrm{a}}$ sessão.

\section{Amostra}

A pesquisa foi realizada com uma equipe de voleibol feminino da categoria mirim pertencente a um clube na cidade de Belo Horizonte, Minas Gerais. Participaram 12 jogadoras, com idade média de 13,9 \pm 0,3 anos e experiência média treinamento da modalidade em clubes de $1,1 \pm 0,8$ anos. A equipe participava das competições metropolitanas e estaduais organizadas pela Federação Mineira de Voleibol (2010). Para essa categoria era adotado o sistema de jogo 4 x 2 sem infiltração, no qual ocorre a separação de funções entre levantadoras e atacantes, conforme o regulamento da Federação Mineira de Voleibol. A frequência de treino consistia em cinco sessões semanais (duração média de uma hora e 30 minutos). No momento da investigação a equipe se encontrava há aproximadamente seis semanas antes do início da primeira competição do ano.

\section{Procedimentos}

A aplicação do teste de conhecimento declarativo da modalidade voleibol aconteceu antes e após 17 sessões de treinamento. Cada uma das 17 sessões foi filmada para posterior análise no laboratório de multimídia do CECA (Centro de Estudos em Cognição e Ação) da Escola de Educação Física, Fisioterapia e Terapia Ocupacional da Universidade Federal de Minas Gerais (EEFFTO/UFMG). Para a realização dos testes de conhecimento tático, foi escolhido dentro das próprias instalações do clube um local afastado de interferências externas, objetivando facilitar a visualização das cenas e manutenção da concentração das voluntárias. Foram dadas instruções para que as voluntárias se concentrassem nas tarefas do teste e evitassem fazer quaisquer comentários durante todo o período de aplicação do mesmo. A duração média do teste, tanto no pré-teste quanto no pós-teste, foi de aproximadamente uma hora.

\section{Teste de conhecimento tático}

Para a avaliação do conhecimento tático utilizouse o Teste de Conhecimento Tático de Vídeo do Voleibol (TCTV-VB), validado por PaUla (2001). O TCTD-VB é composto por 43 cenas que possibilitam analisar o nível de conhecimento tático declarativo do atleta a partir de cenas com situações de ataque de rede no voleibol. As cenas foram retiradas de jogos de equipes masculinas profissionais, sendo que, cada uma delas inicia-se com um saque, oportunizando assim a visualização de recepção, levantamento e ataque. Entretanto, no momento do ataque, a cena é paralisada e após três segundos, a mesma desaparece, não permitindo assim que o voluntário visualize a decisão de ataque do jogador filmado. As cenas eram compostas por situações de ataque de entrada, saída e meio de rede (zonas 4, 2 e 3, respectivamente), existindo a presença de bloqueios simples, duplos e eventualmente triplos. Em nenhuma das cenas ocorreu a participação simultânea de mais de um atacante ou ataque realizado do fundo de quadra, isto é, finalizações realizadas por jogadores que estavam posicionados atrás da linha dos três metros (zonas 1, 5 e 6). Deste modo, os problemas táticos analisados pelas voluntárias do presente estudo assemelham-se aos que emergem recorrentemente no nível de jogo por elas praticado.

Para esta pesquisa foram escolhidas 30 das 43 cenas disponíveis no TCTV-VB, de maneira que 15 cenas foram utilizadas no início da pesquisa (pré-teste) e as outras 15 ao final da mesma (pós-teste). A separação das cenas (pré-teste e pós-teste) teve com o objetivo evitar possíveis efeitos de aprendizagem e memória. Além disto, as cenas possuíam o mesmo nível de dificuldade. Para que as voluntárias pudessem compreender como elaborar as respostas, três cenas das 13 restantes foram mostradas antes de cada dia de teste como forma de exemplos. As atletas tinham em mãos lápis, borracha e um questionário. Após visualizarem cada cena, elas tinham tempo suficiente para elaborar as respostas sobre a situação de jogo apresentada.

As respostas de cada questão se dividem em dois níveis, sendo o primeiro relacionado a que decisão tática deve ser tomada na situação de ataque de rede apresentada - a tomada de decisão (TD), no caso, "atacar" ou "largar" - enquanto que no segundo nível, o voluntário deve escrever uma breve justificativa dessa decisão. As respostas foram registradas nos questionários entregues às participantes.

A correção do teste é feita mediante um gabarito que foi construído a partir de respostas dadas por treinadores de voleibol peritos nesta modalidade, com o nível de concordância de 100\%. Primeiramente, avaliava-se a TD que possui caráter dicotômico, ou seja, se o avaliado errar, não obterá pontos e perderá a possibilidade de ser avaliada a justificativa. Entretanto, se acertar a questão recebe 10 pontos, dando a possibilidade de se avaliar a justificativa. A pontuação 
deste segundo item (justificativa) corresponde à quantidade de sinais relevantes percebidos (bloqueio e defesa), bem como o nível de importância destes para o sucesso desta ação. Sendo assim, o indivíduo pode errar (nenhum ponto), acertar parcialmente (quatro ou seis pontos) ou mesmo acertar integralmente a justificativa (10 pontos). Resumidamente, a pontuação máxima obtida em cada uma das 15 questões é 20 pontos e, portanto, a pontuação máxima a ser alcançada tanto no pré-teste quanto no pós-teste por cada voluntária foi 300 pontos.

Para diminuir a possibilidade de erro de interpretação das justificativas escritas pelas atletas, foi analisada a concordância entre avaliadores através do teste Kappa. Dois professores de Educação Física, com título de treinador nível III regional em voleibol, avaliaram todas as respostas utilizando o gabarito oferecido pelo teste. Foram observados os valores de concordância de 0,95 e 0,97 para o pré-teste e pós-teste, respectivamente $(\mathrm{p}<0,001)$.

\section{Análise das sessões de treinamento técnico-táticos}

Para a análise do processo de ensino-aprendizagemtreinamento adotado pelo treinador, foram filmadas as sessóes de treinamento e posteriormente analisadas através de um sistema de classificação adotado por RAMOS, GRAÇA e NASCIMENTO (2006) no basquetebol e no próprio voleibol por COLLET et al. (2007), NASCIMENTO e Barbosa (2000) e Ramos, Nascimento e Collet (2009). Esse sistema consiste em analisar a condição da tarefa, ou seja, como o treinador transformou os conteúdos técnico-táticos em atividades de treinamento. Para a análise das condições das tarefas, foi possível caracterizar quatro níveis de complexidade:

1) Fundamento individual: exercitação das habilidades técnicas isoladas sem oposição;

2) Combinação de fundamentos: exercitação de duas ou mais habilidades sem oposição;

3) Complexos de jogo: situações de jogo que combinam enfoque tático com o encadeamento de ação de dois ou mais fundamentos. No voleibol, os complexos de jogo têm sido geralmente subdivididos em situações denominadas "side-out" (ponto disputado a partir da recepção do saque, tendo como sequência o levantamento e o ataque) e situações denominadas transição (ponto disputado a partir da defesa do ataque adversário, tendo também como sequência o levantamento e o ataque) (CÉSAR \& Mesquita, 2006; Nascimento \& Barbosa, 2000; Ramos, Nascimento \& Collet, 2009). No presente estudo, assim como feito por NASCIMENTO e Barbosa (2000) e Ramos, Nascimento e Collet (2009), situações de "side-out" foram classificadas como complexo de jogo I e situações de transição como complexo de jogo II. Tanto nas situações de complexo de jogo I quanto complexo de jogo II poderiam ocorrer a continuidade da disputa do ponto, caso a atividade fosse assim organizada pelo treinador. Adicionalmente, os complexos de jogo I e II poderiam ser estruturados com formações completas $(6 \times 6)$ ou mesmo com um número reduzido de jogadores $(2 \times 2,3 \times 3,4 \times 4$ ou $5 \times 5)$.

4) Jogos: exercitações em situação de jogo formal (dentro das regras oficiais).

Assim como no TCTV-VB, foi calculado o nível de concordância através do teste Kappa. Dois dos pesquisadores envolvidos neste estudo assistiram às sessōes de treinamento filmadas e classificaram cada atividade conforme os níveis de complexidade acima descritos, obtendo-se um valor de concordância de $0,95(\mathrm{p}<0,001)$.

\section{Análise estatística}

Para a análise das sessões de treinamento filmadas foi realizada uma análise estatística descritiva relacionada com as atividades desenvolvidas pelo treinador, bem como em relação ao desempenho no TCTV-VB. Para verificar a presença de diferenças no conhecimento tático (TD e justificativa) entre o préteste e o pós-teste, foi utilizado o teste de Wilcoxon, adotando-se um nível de significância de $\mathrm{p}<0,05$.

\section{Resultados}

A TABELA 1 mostra o resumo das atividades realizadas nas 17 sessões de treinamento. Registrou-se 92 atividades, buscando-se classificar cada atividade pela sua característica predominante. A categoria "domínio de bola" se constituiu de atividades sem oposição nas quais as atletas combinavam as técnicas de passe por cima (toque), passe por baixo (manchete) e cortada realizada do solo sem a presença da rede. 
É importante ressaltar que algumas atividades, como por exemplo, aquelas relacionadas ao fundamento levantamento, não foram realizadas por todas as jogadoras, pois nesta categoria o processo de especialização de funções dentro da equipe já se fazia presente.

Em relação à análise das condições das tarefas, verificou-se que $42,1 \%$ do tempo total de treinamento foi utilizado em tarefas classificadas como fundamento individual e $15,4 \%$ como combinação de fundamentos. Os complexos de jogo I e II contribuíram, respectivamente, com $27,7 \%$ e $2,2 \%$ do tempo total de treinamento, enquanto que $12,6 \%$ do tempo foi empregado com jogos. As tarefas classificadas como fundamento individual e combinação de fundamentos adotaram conjuntamente funções de fixação ou diversificação da técnica, enquanto que os complexos de jogos I e II demonstraram função relacionada à aplicação da técnica em contextos próximos às situaçōes de jogos. Assim, apesar das atividades relacionadas ao aperfeiçoamento técnico (fundamento individual e combinação de fundamentos) terem ocupado maior parte do tempo de treinamento analisado $(57,5 \%)$, o segundo grupo de tarefas no qual se dedicou maior tempo foi aquele composto por atividades que enfatizaram o aprendizado tático das voluntárias, representadas no estudo pelos complexos de jogo (29,9\% do tempo total).
Analisando a sequência em que as atividades foram estruturadas, verificou-se que 12 das 17 sessões de treino $(71 \%)$ iniciaram-se com tarefas de fundamento individual ou combinação de fundamentos seguidas de atividades de complexos de jogo. Em duas sessões foram utilizadas apenas atividades de aperfeiçoamento técnico (12\%). Duas outras sessōes foram constituídas somente por jogos (12\%) e uma última sessão apenas por complexos de jogos (6\%). Assim, com base nesta descrição, pode sugerir características predominantemente de um método de treinamento analítico.

A FIGURA 1 apresenta a distribuição dos pontos relacionada à TD no pré-teste e pós-teste. $\mathrm{O}$ somatório do desempenho das 12 atletas foi de 940 pontos para o pré-teste e 1120 pontos para o pós-teste, representando respectivamente um aproveitamento de $52 \%$ e $62 \%$ do total de pontos distribuídos. Ao se comparar a pontuação da TD obtida pelas voluntárias no pré-teste com o pós-teste, não foi verificada diferença estatística $(\mathrm{p}=0,14)$.

Na FIGURA 2 está demonstrada a distribuição dos pontos relacionada a justificativa no pré-teste e no pós-teste. O somatório do desempenho das 12 jogadoras foi de 580,7 e 756 no pré-teste e pós-teste, respectivamente, o que representou um aproveitamento de $32,3 \%$ e $42 \%$ do total de pontos. Semelhante ao que ocorreu na análise da TD, novamente não foi encontrada diferença entre as situações préteste e pós-teste referentes à justificativa $(\mathrm{p}=0,11)$.

TABELA 1 - Frequência de aparecimento das atividades em 17 sessões de treinamento e tempo despendido por cada tipo de atividade.

\begin{tabular}{lcc}
\hline \multicolumn{1}{c}{ Atividades } & Frequência & Tempo (min) \\
\hline Saque & $18(19,6 \%)$ & $201,4(12,9 \%)$ \\
Recepção & $02(2,2 \%)$ & $30,0(1,9 \%)$ \\
Levantamento & $11(12,0 \%)$ & $148,5(9,5 \%)$ \\
Domínio de bola & $13(14,1 \%)$ & $74,8(4,8 \%)$ \\
Ataque & $14(15,2 \%)$ & $198,8(12,8 \%)$ \\
Bloqueio & $07(7,6 \%)$ & $104,6(6,7 \%)$ \\
Defesa & $08(8,7 \%)$ & $138,0(8,9 \%)$ \\
Complexos de jogo & $17(18,5 \%)$ & $465,9(29,9 \%)$ \\
Jogo & $02(2,2 \%)$ & $195,0(12,5 \%)$ \\
\hline Total & $92(100 \%)$ & $1557,0(100 \%)$ \\
\hline
\end{tabular}




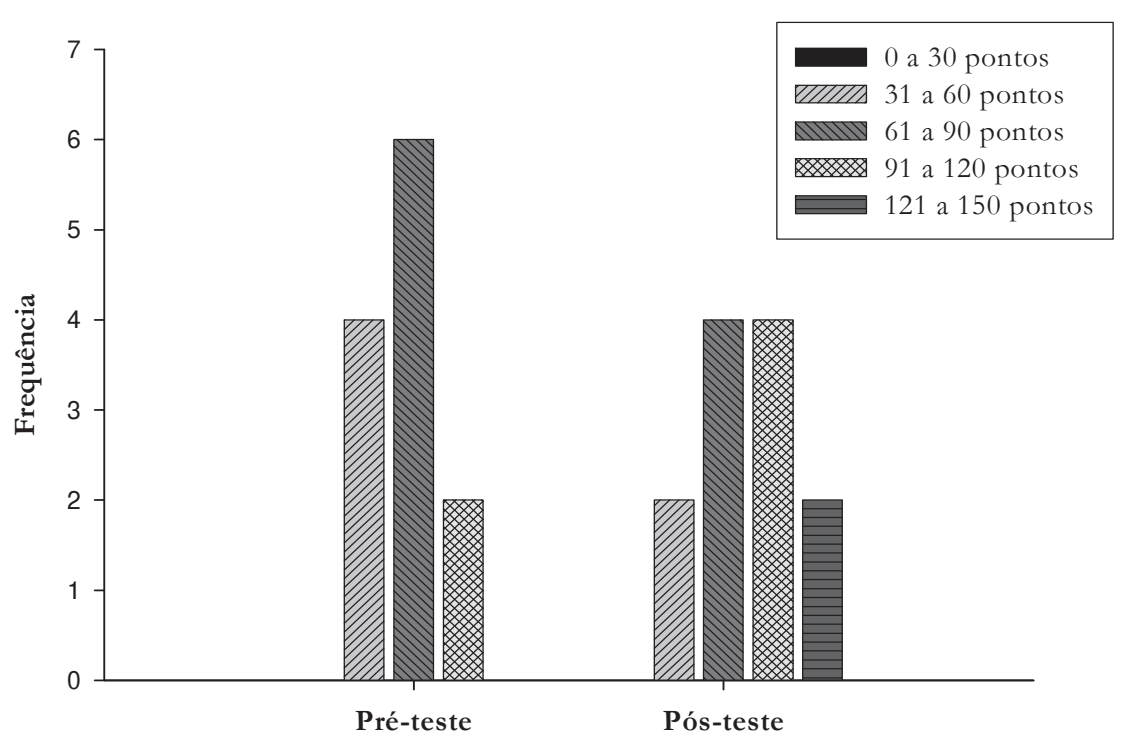

FIGURA 1- Frequência dos pontos da tomada de decisão antes e após 17 sessões de treinamento.

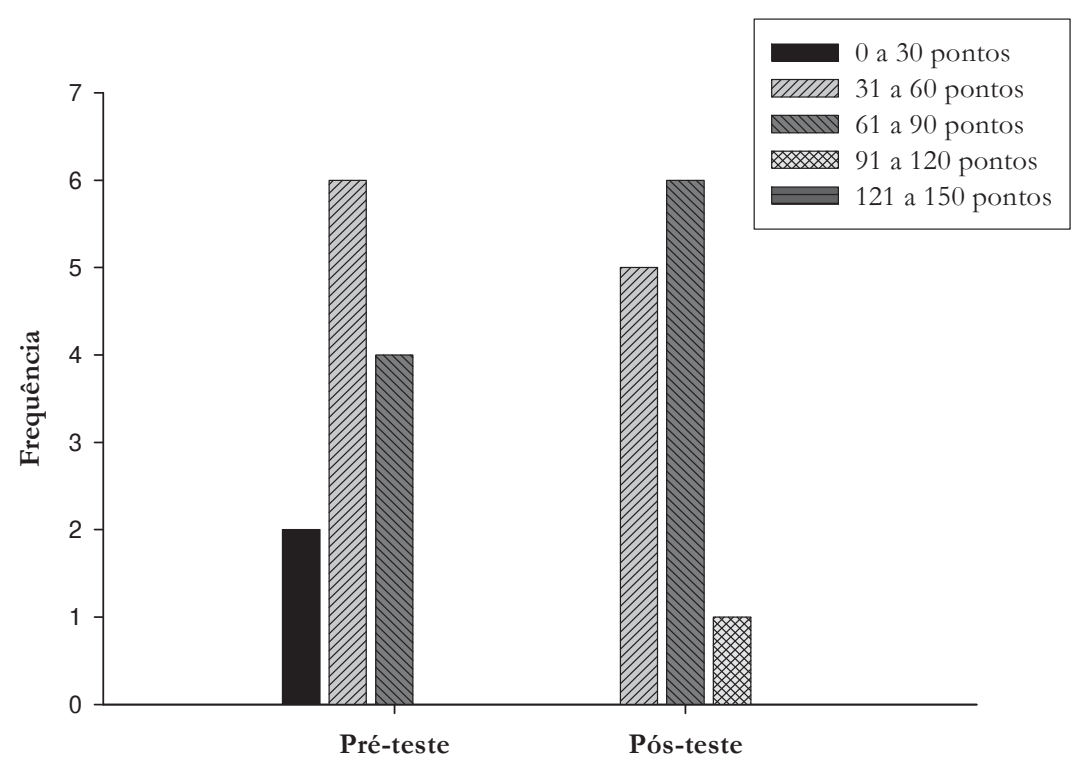

FIGURA 2 - Frequência dos pontos da justificativa antes e após 17 sessões de treinamento.

\section{Discussão}

O objetivo do presente estudo foi verificar em que medida processo de ensino-aprendizagemtreinamento estruturado pelo próprio treinador no decorrer de 17 sessões de treinamento técnico-tático em uma equipe de formação do voleibol pôde favorecer o desenvolvimento do conhecimento tático declarativo das atletas. Não foi verificado aumento do conhecimento tático das voluntárias ao serem submetidas a uma estrutura de treinamento com característica predominantemente analítica.
Lima, Matias, Greco e Greco (2005) utilizaram o teste TCTV-VB ao avaliarem as seleções juvenis de que representavam sete Estados que participavam do Campeonato Brasileiro da divisão principal. A amostra foi composta de 53 atletas do sexo masculino, idade entre 16 e 19 anos. Foi obtido um aproveitamento médio de 78\% no item TD e $64 \%$ no item justificativa, percentuais mais altos que aqueles encontrados em nossa pesquisa. Tal superioridade por parte das seleçōes estaduais pode ser justificada por vários fatores, como 
por exemplo, o maior tempo de prática na modalidadee o nível de desempenho. Enquanto que o tempo médio de prática da equipe voluntária deste estudo foi de 1,1 ano, no estudo de Lima et al. (2005) a seleção com menor experiência média tinha 4,5 anos de prática. Esses dados corroboram com os resultados encontrados por IGLESIAS et al. (2005), que demonstraram correlação positiva e significativa entre conhecimento tático no basquetebol e tempo de experiência nessa modalidade. Embora Costa, Garganta, Fonseca e Botelho (2002) não tenham encontrado diferenças de conhecimento tático entre jogadores de futebol pertencentes a diferentes níveis competitivos, outras pesquisas verificaram relação entre nível de desempenho e conhecimento tático. French e Thomas (1987), investigando o basquetebol, verificaram que crianças mais habilidosas demonstraram maior conhecimento tático que as não habilidosas. Esses resultados são apoiados pelas pesquisas de Del-Villar, Iglesias, Moreno, Fuentes e Cervello (2004) e Iglesias et al. (2005), indicando que os indivíduos mais habilidosos apresentam também maior conhecimento tático da modalidade praticada.

A evolução do desempenho de tomada de decisão em situaçôes reais de jogo parece ser acompanhada pelo desenvolvimento do conhecimento tático do indivíduo (French \& Thomas, 1987; Turner \& MARTINEK, 1999), sendo este último uma das bases para a ação tática habilidosa. No presente estudo não foi verificado aumento em nenhum dos parâmetros relacionados ao conhecimento declarativo após 17 sessões consecutivas de treinamento.

É possível que o número de sessóes de treino no presente estudo tenha sido insuficiente para oportunizar a evolução do conhecimento tático das voluntárias. TURNer e MARTINEK (1992), em um estudo com duração de seis sessōes também não verificaram evolução do conhecimento declarativo e processual relacionado ao hóquei entre escolares (13 e 14 anos). Entretanto, em períodos superiores a nove dias de treinamento, outros estudos verificaram evolução tanto no desempenho tático em situações de jogo (HarRIsON et al., 2004; Mesquita et al., 2005; TURNER \& MARTINEK, 1999) quanto no próprio conhecimento tático dos praticantes (FrENCH et al., 1996; HaRRISON et al., 2004; Martins-Costa et al., 2007; McPherson \& French, 1991; Perez-Morales \& Greco, 2007; Silva \& Greco, 2009; Sisto \& Greco, 1995; Turner \& MartineK, 1999). Esses resultados corroboram as observaçōes feitas por MENDEZ-GiMENEZ (1999), que em uma revisão sobre os métodos de ensino dos jogos esportivos coletivos, verificou que períodos tratamento superiores a 15 sessões são necessários para a evolução do conhecimento tático.

Por outro lado, a literatura tem indicado que métodos de treinamento com ênfase no desenvolvimento tático apontam ser mais apropriados para o desenvolvimento do conhecimento declarativo e processual dos praticantes (FrENCH et al., 1996; GRIFFIN, Ostin \& Mitchell, 1995; McPherson \& French, 1991; Mendez-Gimenez, 1999; Perez-Morales \& Greco 2007; Silva \& Greco, 2009; Sisto \& GreCo, 1995; TURNER \& MARTINEK, 1999), mesmo quando consideradas as modalidades de não-invasão.Nesse sentido, ainda que o tempo de treinamento utilizado pela equipe avaliada possa ter sido suficiente para observar modificações no conhecimento tático, como demonstrado em considerável parte dos estudos, é possível que o processo de ensino-aprendizagemtreinamento não tenha sido adequado para este fim. No presente estudo, o treinador utilizou aproximadamente $30 \%$ do tempo total de treino com as tarefas de ênfase tática, enquanto que $57 \%$ com tarefas de aperfeiçoamento técnico. Além disso, as sequências de elaboração das tarefas (aperfeiçoamento técnico seguido de treinamento tático) também levam a caracterizar o treinamento como sendo mais próximo ao método analítico, que tem como base principal o desenvolvimento da técnica de forma desconectada das situações de jogo (Mesquita, Pereira \& Graça, 2009; Turner \& MartineK, 1992). Portanto, apesar da presença de tempo destinado ao treinamento tático, a ênfase foi de treinamento técnico estruturado aparentemente de forma analítica, o que pode ter sido determinante para encontrarmos tais resultados. Tem-se sugerido que o ensino da técnica seja operacionalizado principalmente através dos contextos do jogo, isto é, de forma situacional (MESQUITA, 2006; Mesquita, Pereira \& GraÇA, 2009), devido à especificidade da aplicação da ação motora nos diferentes momentos do jogo. Esse aspecto ganha maior relevância se considerarmos que as situações do ataque de rede aparentam maior grau de interferência contextual que outras situaçôes do jogo de voleibol, como por exemplo, o saque ou a recepção. Nesse sentido, espera-se que o treinamento técnico executado de forma mais situacional atue de forma privilegiada no aprendizado tático dos praticantes, especialmente do ataque de rede.

Outra questão que também pode explicar a ausência significativa de incremento do conhecimento tático está associada a como o treinador aproveitou as tarefas utilizadas em treino. É possível que, mesmo o treinador tendo utilizado tarefas de treinamento 
tático, ele pode não ter dado a devida ênfase para o desenvolvimento da tomada de decisão. No estudo de Ramos, Graça e Nascimento (2006), foi demonstrado que em determinadas situações de treinamento com ênfase tática (jogos modificados), estagiários de Educação Física buscavam chamar a atenção de seus alunos para o aperfeiçoamento do gesto motor, não aproveitando, portanto, o potencial da tarefa escolhida. No presente estudo não foi utilizado o registro de som (microfone de lapela), como feito por Ramos, Graça e Nascimento (2006), o que dificulta analisar quais foram as características das instruções do treinador durante as tarefas de treino.

A característica do grupo estudado pode ter sido também determinante nos resultados obtidos. Apesar de em boa parte das pesquisas citadas a faixa etária dos voluntários se aproximarem da apresentada no presente estudo, o nível de experiência geralmente não é o mesmo. As voluntárias deste estudo tinham considerável experiência com a modalidade voleibol (média superior a um ano), enquanto que em estudos como de TURner e MarTineK (1999) as voluntárias eram iniciantes no esporte ensinado. Isso é reforçado pelos resultados de HARRISON et al. (2004), em que indivíduos menos habilidosos demonstraram maior evolução de alguns dos parâmetros do conhecimento tático avaliado.

Alguns aspectos relacionados às características do teste de conhecimento tático adotado neste estudo também merecem destaque. Como o TCTV-VB se refere apenas às situações de ataque de rede, pode ser questionado se este conteúdo foi abordado suficientemente durante as sessōes de treinamento ou, mesmo, se a abordagem ocorreu de forma aproximada às situações visualizadas no teste de conhecimento tático. Caso isso não tenha ocorrido, provavelmente não seriam esperadas modificações nos resultados do TCTV-VB. Entretanto, considerável parte do tempo de treinamento envolveu situaçóes de ataque, seja através deste fundamento isolado $(12,8 \%)$ ou através de situações com algum enfoque tático, como nos complexos de jogo $(29,9 \%)$ ou jogos (12,5\%). Além disso, a equipe pertencia a uma categoria onde já existia a divisão de funçōes entre levantadoras e atacantes, favorecendo a existência de situaçóes de ataque que se aproximavam àquelas presentes no teste, como por exemplo, ataques de primeiro tempo realizados pelo meio de rede (zona 3). Portanto, é aceitável que o fundamento ataque tenha sido suficientemente treinado no decorrer do período analisado e que as situaçôes de treinamento estivessem relacionadas àquelas visualizadas no teste de conhecimento tático, ainda que o desempenho técnico-tático das voluntárias fosse efetivamente inferior ao apresentado nas imagens de vídeo. Cabe-se ressaltar, no entanto, que o potencial tático presente nas situações de ataque de rede pode não ter sido desenvolvido durante as sessões de treino, como já alertado anteriormente.

Outra observação sobre o TCTV-VB se refere à particularidade deste instrumento quando comparado com testes de conhecimento utilizados por outros autores. GRIFFIN, OsLIN e MitChell (1995), Harrison et al. (2004) e Turner e Martinek (1992, 1999) utilizaram questionários com perguntas relacionadas às situaçōes de jogo ou regras dos esportes analisados. MARTins-CostA et al. (2007), que também verificaram aumento de um dos parâmetros relacionados ao conhecimento tático declarativo, utilizaram imagens de diagramas como forma de representação das situações de jogo. No presente estudo, o TCTV-VB se caracteriza por analisar situações de jogo filmadas, dependendo, portanto, da capacidade das voluntárias de perceber sinais relevantes da situação em questão para se responder a pergunta realizada. Este aspecto leva o TCTV-VB a ter maior aproximação com a realidade ambiental do jogo, embora, por outro lado, demonstre maior dificuldade de análise, dada a natureza dinâmica e complexa dos cenários apresentados, o que pode em parte explicar os resultados encontrados.

\section{Conclusão}

Conclui-se que, apesar do processo de ensinoaprendizagem-treinamento utilizado pelo treinador não ter demonstrado apenas se centrar no aperfeiçoamento técnico, a maior parte do tempo das 17 sessōes de treino analisadas foi ainda destinada ao aperfeiçoamento do gesto técnico sem conexão com situações de jogo. Além disto, percebe-se que as sequências das atividades realizadas durante os treinos seguiam uma padronização que iniciava com os fundamentos individuais ou combinação de fundamentos, terminando a sessão de treino com o jogo coletivo, o que indica predominantemente a base do método analítico. Possivelmente a característica do processo de ensino-aprendizagem-treinamento 
adotado durante esse período de treinamento não tenha contribuído adequadamente para o aumento do conhecimento tático.

Recomenda-se para estudos futuros que seja analisado este procedimento em outros momentos do processo de treinamento técnico-tático, já que se espera que a ênfase técnica e tática possa variar no decorrer da temporada. Além disso, seria importante registrar as instruções verbais proporcionadas pelo treinador durante os treinamentos, uma vez que esse fator pode influenciar significativamente o processo de ensino-aprendizagem-treinamento utilizado.

\begin{abstract}
Relationship between teaching-learning-training process and the development of tactical knowledge in volleyball

The aim of this study was to verify the extent to which the teaching-learning-training process used in a female volleyball team promoted the development of the tactical knowledge. Twelve female players $(13.9 \pm 0.3$ years) of a volleyball team participated in the study. To characterize the process of teachinglearning-training were video recorded and subsequently analyzed 17 consecutive sessions of technicaltactical training. The test validated by PAULA (2001) was used to verify the development of the declarative tactical knowledge and it was applied at the beginning and the end of the registered training sessions. When analyzing the training sessions, activities related to the development of technical capacity occupied $57.5 \%$ of total time of training, while in $29.9 \%$ of total time was developed activities with tactical characteristics. There was no increase in any of the variables measured in the tactical knowledge test. The results demonstrated that the coach prepared training sessions dedicating more attention to the technical component, which is shown particularly through the activities without association with game situations, as "individual skills" and "skills combination". The training design used does not seem to have helped to increase the declarative tactical knowledge during the study period.
\end{abstract}

UNITERMS: Teaching models; Team sports; Cognition and action; Decision making.

\title{
Referências
}

ANDERSON, J.R. Psicologia cognitiva e suas implicaçôes experimentais. Rio de Janeiro: LTC, 2004.

CÉSAR, B.; MESQUITA, I. Caracterização do ataque do jogador oposto em função do complexo do jogo, do tempo e do efeito do ataque: estudo aplicado no voleibol feminino de elite. Revista Brasileira de Educação Física e Esporte, São Paulo, v.20, n.1, p.59-69, 2006. COLLET, C.; NASCIMENTO, J.V.; RAMOS, M.H.K.; DONEGÁ, A.L. Processo de ensino-aprendizagem-treinamento no voleibol infantil masculino em Santa Catarina. Revista da Educação Física, Maringá, v.18, n.2, p.147-59, 2007. CORRÊA, U.C.; SILVA, A.S.; PAROLI, R. Efeito de diferentes métodos de ensino na aprendizagem do futebol de salão. Motriz, Rio Claro, v.10, n.2, p.79-88, 2004.

COSTA, J.C.; GARGANTA, J.; FONSECA, A.; BOTELHO, M. Inteligência e conhecimento específico em jovens futebolistas de diferentes níveis competitivos. Revista Portuguesa de Ciências do Desporto, Porto, v.3, n.4, p.7-20, 2002. DEL-VILLAR, F.; IGLESIAS, D.; MORENO, M.P.; FUENTES, J.P.; CERVELLO, E.M. An investigation into procedural knowledge and decision-making: Spanish experienced-inexperienced basketball players differences. Journal of Human Movement Studies, London, v.46, n.5, p.407-20, 2004.

FEDERAÇÃO MINEIRA DE VOLEIBOL. Regulamento geral 2010. Disponível em: <http://www.fmvolei.org.br/>. Acesso em: 15 mai. 2010.

FRENCH, K.E.; THOMAS, J.R. The relation of knowledge development to children's basketball performance. Journal of Sport Psychology, Champaign, v.9, p.15-32, 1987.

FRENCH, K.E; WERNER, P.H.; TAYLOR, K.; HUSSEY, K.; JONES, J. The effects of a 6 week unit of tactical, skill, or combined tactical and skill instruction on badminton performance of ninth-grade students. Journal of Teaching Physical Education, Champaign, v.15, p.439-63, 1996. 
GARGANTA, J. Para uma teoria dos jogos desportivos colectivos. In: GRAÇA, A.; OLIVEIRA, J. O ensino dos jogos desportivos colectivos. Porto: Centro de Estudos dos Jogos Desportivos/Universidade do Porto, 1995.

GRECO, P.J. Cogniçáo e açáo: novos conceitos em treinamento esportivo (CENESP-UFMG). Belo Horizonte: INDESP, 1999. p.119-54. GRECO, P.J.; BENDA, R.N. Iniciação esportiva universal 1: da aprendizagem motora ao treinamento técnico. Belo Horizonte: Editora UFMG, 1998.

GRECO, P.J.; CHAGAS, M.H. Considerações teóricas da tática nos jogos esportivos coletivos. Revista Paulista de Educação Física, São Paulo, v.6, n.2, p.47-59, 1992.

GRIFFIN, L.L.; OSLIN, J.L.; MITCHELL, S.A. Analysis of two instructional approaches to teaching net games. Research Quarterly for Exercise and Sport, Washington, v.66, 1995. Supplement A-64.

HARRISON, J.M.; BLAKEMORE, R.P.; RICHARDS, J.O.; OLIVER, J.; WILKINSON, C.; FELLINGHAM, G.W. The effects of two instructional models - tactical and skill teaching - on skill development and game play, knowledge, self-efficacy, and student perceptions in volleyball. The Physical Educator, Indianopolis, v.61, n.4, p.186-99, 2004.

IGLESIAS, D.; MORENO, M.P.; SANTOS-ROSA, F; CERVELLO, E.M.; DEL-VILLAR, F. Cognitive expertise in sport: Relationships between procedural knowledge, experience and performance in youth basketball. Journal of Human Movement Studies, London, v.49, n.1, p.65-76, 2005.

LIMA, C.O.V.; MATIAS, C.J.A.S.; GRECO, F.L.; GRECO, P.J. Conhecimento tático declarativo: uma análise no campeonato brasileiro de seleções masculinas juvenis de Voleibol. Revista Mineira de Educação Física, Viçosa, v.13, n.2, p. 135-42, 2005. MARTINS-COSTA, H.C.; LIMA, C.O.V.; MATIAS, C.J.A.S.; GRECO, P. J. Efeito do processo de treinamento técnicotático no nível de conhecimento tático declarativo de jovens praticantes de voleibol. Revista Mineira de Educação Física, Viçosa, v.15, n.2, p.5-19, 2007.

McPHERSON, S.L.; FRENCH, K.E. Changes in cognitive strategies and motor skill in tennis. Journal of Sport and Exercise Psychology, Champaign, v.13, p.26-41, 1991.

MÉNDEZ-GIMÉNEZ, A. Modelos de enseñanza deportiva: análise de dos decadas de investigacion. Lecturas: Educacion Física y Deportes, Buenos Aires, v.4, n.13, 1999. Disponível em: <http://www.efdeportes.com/>. Acesso em: 03 mai. 2004. MESQUITA, I. Contributo para a estruturação das tarefas no treino em voleibol. In: OLIVEIRA, J.; TAVARES, F. Estratégia e táctica nos jogos deportivos colectivos. Porto: Centro de Estudos dos Jogos Desportivos/Universidade do Porto, 1996. Ensinar bem para aprender melhor o jogo de voleibol. In: TANI, G.; BENTO, J.O.; PETERSON, R. Pedagogia do desporto. Rio de Janeiro: Guanabara Koogan, 2006. p.327-44.

MESQUITA, I.; GRAÇA, A.; GOMES, A.R.; CRUZ, C. Examining the impact of a step game approach to teaching volleyball on student tactical decision making and skill execution during game play. Journal of Human Movement Studies, London, v.48, n.6, p.469-92, 2005.

MESQUITA, I.; PEREIRA, F.R.M.; GRAÇA, A.R. Modelos de ensino dos jogos desportivos: investigação e ilações para a prática. Motriz, Rio Claro, v.5. n.4, p.944-54, 2009.

MOREIRA, V.J.P. A influência de processos metodológicos de ensino-aprendizagem-treinamento (E-A-T) na aquisição do conhecimento tático no futsal. 2005. Dissertação (Mestrado) - Universidade Federal de Minas Gerais, Belo Horizonte, 2005. NASCIMENTO, J.A.; BARBOSA, G.B. Estruturação das sessões técnico-táticas no voleibol infanto-juvenil e juvenil feminino: um estudo de caso. In: SIMPÓSIO NACIONAL DE EDUCAÇÃO FÍSICA, 19., 2000, Pelotas. Anais... Pelotas: Universitária, 2000. p.115-23.

PAULA, P. Processo de validação de teste para avaliar a capacidade e o conhecimento declarativo no voleibol: situações de ataque de rede. 2001. Dissertação (Mestrado) - Universidade Federal de Minas Gerais, Belo Horizonte, 2001.

PEREZ-MORALES, J.C.; GRECO, P.J. A influência de diferentes metodologias de ensino-aprendizagem-treinamento no basquetebol sobre o nível de conhecimento tático processual. Revista Brasileira de Educação Física e Esporte, São Paulo, v.21, n.4, p.291-99, 2007.

RAMOS, M.H.K.P.; NASCIMENTO, J.V.; COLLET, C. Avaliação do desenvolvimento das habilidades técnico-táticas em equipes de voleibol infantil masculino. Revista Brasileira de Cineantropometria e Desempenho Humano, Florianópolis, v.11, n.2, p.181-9, 2009.

RAMOS, V.; GRAÇA, A; NASCIMENTO, J.V. A representação do ensino do basquetebol em contexto escolar: estudos de casos na formação inicial em educação física. Revista Brasileira de Educação Física e Esporte, São Paulo, v.20, n.1, p.37-49, 2006.

SAAD, M.A. Estruturação das sessóes de treinamento técnico-tático nos escalóes de formação do futsal. 2002. Dissertação (Mestrado) - Centro de Educação Física e Desporto, Universidade Federal de Santa Catarina, Florianópolis, 2002. SILVA. M.V.; GRECO, P.J. A influência dos métodos de ensino-aprendizagem-treinamento no desenvolvimento da inteligência e criatividade tática em atletas de futsal. Revista Brasileira de Educação Física e Esporte, São Paulo, v.23, n.3, p.297-307, 2009. 
SISTO, F.F.; GRECO, P.J. Comportamento tático nos jogos esportivos coletivos. Revista Paulista de Educação Física, São Paulo, v.1, n.9, p.63-8, 1995.

STERNBERG, R.J. Psicologia cognitiva. Porto Alegre: Artmed, 2000.

TAVARES. F.; GRECO, P.J.; GARGANTA, J. Perceber, conhecer, decidir e agir nos jogos desportivos coletivos. In: TANI, G.; BENTO, J.O.; PETERSON, R. Pedagogia do desporto. Rio de Janeiro: Guanabara Koogan, 2006. p.284-98.

TURNER, A.P.; MARTINEK, T.J. A comparative analysis of two models for teaching games -technique approach and gamecentered (tactical focus) approach. International Journal of Physical Education, Schorndorf, v.29, n.4, p.15-31, 1992. . An investigation into teaching games for understanding: effects on skill, knowledge, and game play. Research

Quarterly for Exercise and Sport, Washington, v.70, n.3, p.286-96, 1999.

ENDEREÇO

Cláudio Olivio Vilela Lima

R. Leôncio Chagas, 100 - apto. 401

31170-590 - Belo Horizonte - MG - BRASIL

e-mail: claudiovolei@yahoo.com.br

Recebido para publicação: 28/ 04/ 2009

1a. Revisão: $13 / 07 / 2010$

2a. Revisão: 01/ 02/2011

3a. Revisão: 02/03/2011

Aceito: 22/03/2011

Rev. bras. Educ. Fís. Esporte, São Paulo, v.25, n.2, p.251-61, abr./jun. 2011 • 261 